Research Paper:

\title{
The Knowledge, Attitudes, and Practices of Healthcare Providers About Colorectal Cancer Screening by Health Belief Model
}

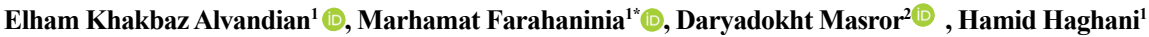

1. Department of Community Health Nursing, School of Nursing and Midwifery, Iran University of Medical Sciences and Health Services, Tehran, Iran 2. Department of Medical-Surgical Nursing, , School of Nursing and Midwifery, Iran University of Medical Sciences and Health Services, Tehran, Iran.

\begin{tabular}{|l|l|}
\hline $\begin{array}{l}\text { Use yourdevice to scan } \\
\text { and read the article online }\end{array}$ & $\begin{array}{l}\text { Cltation: Khakbaz Alvandian, E., et al. 2019. The Knowledge, Attitudes, and Practices of Healthcare Providers About } \\
\text { Colorectal Cancer Screening by Health Belief Model. Journal of Client-Centered Nursing Care, 5(3), pp. 157-166. https://doi. } \\
\text { org/10.32598/JCCNC.5.3.157 }\end{array}$ \\
\hline
\end{tabular}

\section{(c) (1) (3)}

Article info:

Received: 19 Feb 2019

Accepted: 25 Jun 2019

Published: 01 Aug 2019

Keywords:

Knowledge, Attitudes, Colon cancer screening, Health belief model

\begin{abstract}
A B S T RA C T
Background: Colorectal Cancer (CRC) is a serious health problem, and its early detection is crucial for treatment and reducing mortality. Beliefs related to colorectal cancer are an affecting factor in a person's decision about the CRC Program. The current study aimed at assessing the knowledge, attitude, and practice of healthcare providers regarding colorectal cancer screening based on the Health Belief Model (HBM) in Hamedan City, Iran, in 2018.
\end{abstract}

Methods: This was a descriptive cross-sectional study. A total of 330 healthcare workers employed in comprehensive centers of urban and rural services in Hamedan were recruited by the census method. The required data were collected by demographic characteristics form and HBM scale of CRC. To analyze the obtained data, frequency, mean, standard deviation, Independent Samples t-test, Analysis of Variance (ANOVA), linear regression, and logistic regression analyses were used in SPSS.

Results: The achieved results suggested that the mean knowledge score of the study subjects was 10.19; it was higher than that of 7.5 in the structure of HBM. The mean score of perceived sensitivity, perceived severity, perceived benefits, and perceived self-efficacy was higher than that of the perceived tool, and the barriers were less. Test performance was satisfactory in people aged $>50$ years $(68.2 \%)$, and more than $90 \%$ of individuals recommended screening to their clients. They received the most information during training sessions.

Conclusion: Although the level of knowledge of CRC was higher than the average, more education is required for people to receive regarding HBM. On-job training classes should be more precise. Furthermore, considering the favorable performance of the sample, integrating the CRC screening program into the healthcare program has provided desirable results and could be a starting point for other programs.

* Corresponding Author: 


\section{Highlights}

- Colorectal cancer is the third most common cancer in men, the second in women, and is the third leading cause of cancer deaths.

- If colorectal cancer is detected in the early stages, the 5-year survival rate is increased to $90 \%$.

- Due to the lack of screening programs in many countries, only $39 \%$ of early colon cancers are identified.

- The early detection or secondary prevention of cancer is highly important for controlling specific cancers, like the colorectal type.

- People's health beliefs significantly affect their health, including behaviors preventing illnesses or screening.

\section{Plain Language Summary}

Cancer incidence in developing countries is reported to be increasing due to aging populations, changing lifestyles, smoking habits, immobility, and the westernization of diet. Beliefs related to colorectal cancer are a factor impacting a person's decision about the colorectal cancer program. This study discussed the knowledge, attitudes, and practices of healthcare providers about colorectal cancer screening based on HBM. The study results reported that the knowledge of colorectal cancer was higher than the average. Test performance was also satisfactory in people aged over 50 years. Integrating the colorectal cancer screening program into the healthcare programs has had good results and could be a starting point for other programs.

\section{Introduction}

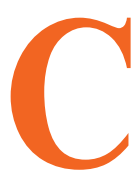

olorectal Cancer (CRC) is a major health problem and the third most common cancer in men and the second in women, as well as the third leading cause of cancer deaths (700000 deaths annually) (Bray et al. 2018; Siegel, Miller \& Jemal 2019).

According to the American Cancer Prevention Institute, in 2018, 1.8 million people were diagnosed with cancer every year, with lung cancer at the first incidence rate of 2.9 million cases per year; breast cancer with 2.09 million and CRC with 1.8 million, followed by the highest annual rate of lung cancer with 1.76 million and colorectal cancer with 862,000. Additionally, 783000 individuals have gastric cancer. Based on the statistics, the most frequent cancers in women are breast, colorectal, and cervical types; lung cancer, prostate cancer, and CRC are the most prevalent cancers in men (Siegel, Miller \& Jemal 2019). Cancer incidence in developing countries is increasing due to aging populations, changing lifestyles, smoking habits, immobility, and the westernization of diets (Bidouei et al. 2014; Jemal et al. 2011).

In Iran, the ongoing epidemiological, demographic transition is effectively turning the pattern of mortality and disability, especially for non-communicable and chronic diseases, aging problems, and cancers to a public health issue in the near and far future (Zendehdel, 2019). According to the Ministry of Health and Medical Education, cancer is the third leading cause of death after cardiovascular diseases and road accidents (Karimy et al. 2012). In a 4-year study performed in Iran between 2005 and 2009, the Age-Specific Rate (ASR) of CRC was reported to be 38 per 100000; much higher than that in other Asian countries (Azadeh et al. 2008; Azadeh et al. 2012; Moghimi-Dehkordi \& Safaee 2012). Current statistics highlight that CRC in Hamedan Province was found to be $4.8 \%$ in women and $8 \%$ in men in 2008 , as well as $7.6 \%$ in women and $11 \%$ in men in 2013 (Hamedan University of Medical Sciences, 2015). In Asia as a whole, treatment has not made much progress in the last decade, with a 5 -year survival rate of about $60 \%$.

The highest and lowest survival rates have been reported in China and India, respectively (Ghazali et al. 2010; Shouri Bidgoli et al. 2015). If CRC is detected in the early stages, the 5-year survival rate is increased to $90 \%$ (Jemal et al. 2011, Bidouei et al. 2014). However, due to the lack of screening programs in many countries, only $39 \%$ of early colon cancers are identified (Moradi et al. 2009; Safaee et al. 2010; Wang et al. 2017). Although various studies have identified several risk factors that can predict patients' survival after diagnosis, life expec- 
tancy has not increased significantly. The early detection or secondary prevention of cancer is highly important for controlling specific cancers, like CRC (Almadi \& Alghamdi 2019). CRC is among the cancers that can be greatly prevented by early detection (Fatemi et al. 2010; Safaee et al. 2010; De Moor et al. 2018). Early detection of cancer is possible with adequate screening programs available (Hamedan University of Medical Sciences, 2015; Zendehdel 2019). Regular screening in individuals aged $>50$ years is the key to colorectal cancer prevention. The US Cancer Prevention Institute suggests using highsensitivity fecal occult blood testing, sigmoidoscopy, or colonoscopy at ages 50-75 years for screening CRC (DeSantis et al. 2019).

People more prone to develop CRC should be screened at a younger age and more frequently. The decision to perform a screening test in individuals aged $>75$ years is based on the patient's own decision (Bidouei et al. 2014; Mansour-Ghanaei et al. 2015). The early detection of CRC reduces mortality. Although periodic screening with Fecal Occult Blood Test (FOBT), sigmoidoscopy, and colonoscopy has been suggested for the early detection of CRC, the screening rate is extremely low (Mansour-Ghanaei et al. 2015; DeSantis et al. 2019).

Tylor argues that the reason for people's non-participation in screening is justified by the Health Belief Model (HBM) (Taylor et al. 2010). The HBM is among the theories developed exclusively for health behaviors. Besides, according to this theory, people's health beliefs significantly impact their health behaviors, including applying HBM in preventing illnesses or screening (Karimy et al. 2012). This model has 6 constructs, including perceived susceptibility, perceived severity, perceived barriers, perceived benefits, perceived self-efficacy, and guidance for action. According to this model, people's sensitivity to a subject or disease is largely dependent on their individual knowledge Safaee et al. 2010; Skinner et al. 2015).

Moreover, understanding the severity of a subject depends on the personal beliefs and mental effects that the illness or condition has on the individual. The combination of perceived sensitivity and perceived severity is called a perceived threat (Shouri Bidgoli et al. 2015). In each task, individuals usually choose the most beneficial behaviors to them, i.e. accessible to the community (Taylor et al. 2010). Perceived barriers are associated with treatment characteristics and preventive measures that may be embarrassing, expensive, unpleasant, or painful to conduct. This attribute can guide a person to avoid taking a desirable action (Skinner et al. 2015). Belief in a fruitful behavior leads to self-efficacy; the belief that leads a person to execute the desired behavior successfully, and expects the results to be achieved (Saffari.M, 2011). Glanz believes that if people recognize the probability of various complications in their lives (perceived susceptibility) and what behaviors reduce risk (perceived barriers), they can overcome factors, such as cost and time (Glanz, Rimer \& Viswanath 2008).

Various research studies have been conducted globally, relying on the constructs of the HBM to determine how people's perception of a subject may impact its screening (Shouri Bidgoli et al. 2015). A study suggested that people were unaware of CRC and its screening, failed to understand the sensitivity of the subject, and only performed 4\% screening. Such data indicate a link between people's knowledge and attitude and its impact on their performance (Bidouei et al. 2014). Although the knowledge of nurses and physicians was high in the study of Rim et al. only $52 \%$ performed screening, and $26 \%$ recommended screening to their clients (Rim et al. 2009). A study about CRC screening in Iran examined knowledge, attitude, and practice in people aged $\geq 50$ years. It was concluded that people had the lowest sensitivity score and only 5\% performed CRC screening (Shouri Bidgoli et al. 2015). Several studies overlooked high knowledge as an effective factor in screening and have regarded people's attitudes to be more effective in this respect (Abuadas, Petro-Nustas \& Abuadas. 2018; Almadi \& Alghamdi 2019). However, some studies reported greater knowledge and higher self-efficacy as a result of increased performance (Christou \& Thompson 2012).

According to Gholampour et al. healthcare providers played a key role in the $\mathrm{CRC}$ screening behavior process by raising their clients' awareness and signifying physicians' advice (Gholampour et al. 2018).

In Iran, the program of basic non-communicable disease interventions aiming to care for middle-aged and older people was announced by the Ministry of Health and Medical Education to the universities and healthcare centers for an integrated urban and rural health plan in 2017. A part of this program comprises screening for CRC and performing secret blood stool testing in people aged 50-69 years. This cancer was selected because of its high preventable nature; in other words, healthcare personnel readiness program to identify high-risk patients with suspected symptoms and their timely referral to the second tier is on the agenda; the training of all healthcare personnel and family physicians is emphasized (Ministry of Health and Medical Education, 2017). Studies in other countries have indicated that healthcare providers failed to perform well on their own, despite their aware- 
ness of CRC and its screening methods; also, they have advised it less frequently to their clients (Ramos et al. 2010; Almadi \& Alghamdi 2019; DeSantis et al. 2019). Thus, this study aimed to investigate the knowledge, attitude, and practices of healthcare providers on screening CRC based on HBM in Hamedan City, Iran, in 2018.

\section{Materials and Methods}

This descriptive cross-sectional study was conducted in 2018. The study population consisted of professional healthcare providers, primary health staff working at health homes (Behvarzes in Iran), as well as midwives and family physicians in Hamadan, comprehensive urban and rural health centers. A total of 390 healthcare providers were selected by the census method. Questionnaires were distributed to staff members during training sessions and visits to the centers, after explaining the study objectives, common terminologies, and confidentiality of the information. The questionnaire took 15 minutes to complete. The study data collection tool was derived from the Champion Health Belief Model Scales (CHBMS) developed by Champion in 1994-1993 for breast cancer screening. It has been used by several researchers in different countries. In 2002, it was first used by Jacobs for colorectal cancer (Kharameh, Foroozanfar \& Zamanian 2014). It was then used by researchers, such as Hou, Ozsoy, Kharameh (Hou, 2005; Ozsoy et al., 2007; Kharameh et al., 2014) for screening CRC based on the HBM. The applied tool was obtained from Tahmasebi et al. (2016) questionnaire; its translation, validity, and reliability have been assessed in Iran. Cronbach's alpha coefficient for HBM constructs was reported as 0.69 to 0.90 , and it was 0.78 . for the whole scale.

The data collection tool consisted of demographic characteristics form, including 18 questions about age, family history of CRC, education, number of children, occupation, etc. The second part of the questionnaire consisted of 15 items, including knowledge about CRC and its screening. One point was assigned to each correct answer and zero for each wrong question and 15 points in total (knowledge question). There were 48 attitude questions with a 5-point Likert-type scale from strongly agree ( 5 points) to strongly disagree ( 1 score), including perceived sensitivity (4 questions) with a score range of (4-20), perceived severity (14 questions) with a score range of 14-70; perceived benefits (8 questions) with a score range of 8-40; perceived barriers (16 questions) with a score range of $16-80$, and perceived self-efficacy (6 questions) with a score range of 6-30.
The greater perceived susceptibility, perceived severity, perceived benefits, and perceived self-efficacy, and the lesser perceived barriers indicated a more favorable attitude toward CRC screening. The performance part consisted of 3 yes/no questions. The positive answers were considered as good, and negative ones were regarded as poor performance, which was expressed on 0-100 (Tahmasebi et al. 2016). Finally, 350 questionnaires were collected, of which 330 were completed.

Data analysis was performed in SPSS in two Independent sections, including descriptive and inferential statistics. Furthermore, the significance level was set at $\mathrm{P}<0.05$. The descriptive statistics section included frequency distribution and frequency percentage for qualitative variables and maximum numerical indices, cumulative frequency percentage, the mean and standard deviation for quantitative variables. Inferential statistics included Independent Samples t-test, the Analysis of Variance (ANOVA), Chi-squared test, multiple linear regression, and logistic regression analyses.

\section{Results}

The study participants' age ranged from 21-55 years; most of them were 30-39 years old, 77\% were female, and $40.9 \%$ had an associate degree (Table 1). Other demographic characteristics are illustrated in Table 2.

The study subjects' mean knowledge score was 10.19 , i.e. higher than the tool's mean value (7.5), and men's knowledge was significantly higher than that of women ( $\mathrm{P}=0.026)$; healthcare workers' knowledge was also higher than that of the primary health providers $(\mathrm{P}=0.022)$. Regarding the mean values of constructs, perceived sensitivity, perceived severity, perceived benefits, and perceived self-efficacy were above tool average; however, the mean score of perceived barriers was below the average. Those with a family history of cancer had higher perceived severity and lowered perceived barriers $(\mathrm{P}=0.021)$. Those with a history of referral to a physician due to gastrointestinal problems had higher perceived severity and perceived self-efficacy $(\mathrm{P}=0.042)$. Besides, physicians, compared to primary health providers, reported higher self-efficacy $(\mathrm{P}=0.04)$ (Table 3$)$.

In addition, the study participants received the most information through in-service education (68.6\%). Abdominal pain (29.3\%), difficulty with defecation (28.6\%), and stool blood (28\%) were the most prevalent symptoms of the screening test (Table 4). Performance assessment data suggested that the individuals aged $\geq 50$ had performed screening with FBOT at $68.2 \%$. The in- 
Table 1. Demographic characteristics of studied healthcare providers

\begin{tabular}{|c|c|c|}
\hline \multicolumn{2}{|c|}{ Variables } & \multirow{2}{*}{\begin{tabular}{|l|} 
No. (\%) \\
$76(23)$
\end{tabular}} \\
\hline & Male & \\
\hline Gender & & \\
\hline & Female & $254(77)$ \\
\hline \multirow{5}{*}{ Age } & $20-29$ & 49 (14.7) \\
\hline & $30-39$ & 145 (43.9) \\
\hline & & \\
\hline & $40-49$ & $114(34.5)$ \\
\hline & $>50$ & $22(6.7)$ \\
\hline \multirow{3}{*}{ Marital status } & Single & $68(20.6)$ \\
\hline & Married & $256(77.6)$ \\
\hline & Divorced & $6(1.8)$ \\
\hline \multirow{7}{*}{ Education } & Elementary school & $6(1.8)$ \\
\hline & Secondary school & $24(7.3)$ \\
\hline & Diploma & $44(13.3)$ \\
\hline & Associate degree & $78(23.6)$ \\
\hline & BA. & 135 (40.9) \\
\hline & MA. & $16(7.6)$ \\
\hline & PhD. & $27(8.1)$ \\
\hline \multirow{5}{*}{ Body Mass Index (BMI) } & $16.5-18.49$ & $4(1.2)$ \\
\hline & $18.5-24.99$ & $156(47.3)$ \\
\hline & $25-29.99$ & $130(39.4)$ \\
\hline & $30-35.99$ & $36(10.9)$ \\
\hline & $>35$ & $4(1.2)$ \\
\hline \multirow{4}{*}{ Job } & Healthcare provider & $182(55.5)$ \\
\hline & Primary health provider & $81(24.5)$ \\
\hline & Midwife & 40 (12.1) \\
\hline & Physician & $37(8.2)$ \\
\hline
\end{tabular}

Client- Centered Nursing Care

tention to conduct screening in the coming months was $45.2 \%$, and $91.8 \%$ recommended their clients to undergo screening (Table 5).

\section{Discussion}

This study assessed the knowledge, attitude, and performance of healthcare providers on CRC screening based on the HBM in Hamedan City, Iran, in 2018. The obtained results indicated that the majority of study participants were well informed of CRC and its screening, which were consistent with similar studies on physicians and nurses. (Rim et al. 2009; Ramos et al. 2010). In the study of Wang et al. the knowledge of women, those with a higher level of educa- 
Table 2. Demographic characteristics of studied healthcare providers

\begin{tabular}{|c|c|c|}
\hline \multicolumn{2}{|l|}{ Variables } & \multirow{2}{*}{$\begin{array}{c}\text { No. (\%) } \\
10(3)\end{array}$} \\
\hline & Yes & \\
\hline Tobacco and clgarette smoking & No & $320(97)$ \\
\hline \multirow{2}{*}{ Alcohol consumption } & Yes & $5(1.5)$ \\
\hline & No & $325(98.5)$ \\
\hline \multirow{2}{*}{ Referral to a physician for digestive probler } & Yes & $137(41.5)$ \\
\hline & No & $192(58.2)$ \\
\hline \multirow{2}{*}{ Changes in evacuation in the last yea } & Yes & $60(18.2)$ \\
\hline & No & $280(81.8)$ \\
\hline \multirow{2}{*}{ Family history of cancer } & Yes & $94(28.5)$ \\
\hline & No & $236(75.5)$ \\
\hline \multirow{2}{*}{ The individual history of cancer } & Yes & $4(1.2)$ \\
\hline & No & $326(98.8)$ \\
\hline \multirow{2}{*}{ Vegetable and fruit consumption } & $<3$ times & $93(28.2)$ \\
\hline & $>3$ times & $237(71.8)$ \\
\hline \multirow{3}{*}{ Physical exercises per week } & No exercise & $130(31.2)$ \\
\hline & $<150 \min$ & $149(45.2)$ \\
\hline & $>150 \mathrm{~min}$ & $78(23.6)$ \\
\hline
\end{tabular}

Client- Centered Nursing Care

tion, and those with a family history of colorectal cancer were higher than that of others (Wang et al. 2017).

In our study, the study participants' attitudes toward CRC and its screening were measured using the HBM constructs; the related results revealed that their perceived sensitivity was higher than the mean value of the instrument, indicating that they were sensitive to $\mathrm{CRC}$ and its screening. In the study of Rim et al. (2009) and Ramos et al. (2010), it was also

Table 3. Statistics of knowledge and attitude in studied healthcare providers

\begin{tabular}{|c|c|c|c|c|c|c|}
\hline Variables & Mean $\pm S D$ & Max. & Min. & $\begin{array}{l}\text { Number of } \\
\text { Questions }\end{array}$ & $\begin{array}{c}\text { Mean of } \\
(1-5)\end{array}$ & SD of (1-5) \\
\hline Knowledge & $10.19 \pm 2.39$ & 15 & 0 & 15 & - & - \\
\hline $\begin{array}{l}\text { Perceived } \\
\text { sensitivity }\end{array}$ & $11.25 \pm 2.82$ & 20 & 4 & 4 & 2.81 & 0.7 \\
\hline Perceived severity & $49.89 \pm 9.43$ & 70 & 14 & 14 & 3.5 & 0.67 \\
\hline Perceived barriers & $35.46 \pm 11.19$ & 80 & 16 & 16 & 2.2 & 0.7 \\
\hline Perceived benefits & $33.01 \pm 5.44$ & 40 & 8 & 8 & 4.1 & 0.68 \\
\hline $\begin{array}{l}\text { Perceived } \\
\text { self-efficacy }\end{array}$ & $24.86 \pm 4.6$ & 30 & 6 & 6 & 4.1 & 0.7 \\
\hline
\end{tabular}


Table 4. The statistics of studied healthcare providers' screening performance for CRC

\begin{tabular}{|c|c|c|}
\hline \multicolumn{2}{|c|}{ Variables } & No. (\%) \\
\hline \multirow{7}{*}{$\begin{array}{l}\text { Source of obtaining information on } \\
\text { colorectal cancer and its screening }\end{array}$} & Radio and TV & $37(12.3)$ \\
\hline & Newspaper and magazine & $11(3.6)$ \\
\hline & Book and notebook & $100(33.3)$ \\
\hline & On-job training classes & $206(68.8)$ \\
\hline & Coworkers & $49(16.3)$ \\
\hline & Friends and relatives & $6(2)$ \\
\hline & Family & $13(4.3)$ \\
\hline \multirow{9}{*}{$\begin{array}{l}\text { Reasons to perform a colorectal } \\
\text { cancer screening test }\end{array}$} & Feeling pain in the abdomen & $2(8)$ \\
\hline & Stool blood & $24(29.3)$ \\
\hline & Bowel defecation problem & $88(28)$ \\
\hline & Periodic check-up & $84(28.6)$ \\
\hline & Physician's recommendation & $86(25)$ \\
\hline & Family history & $75(16)$ \\
\hline & Family recommendation & $48(0.3)$ \\
\hline & Friends' recommendation & $3(22)$ \\
\hline & None & $66(21)$ \\
\hline
\end{tabular}

Client- Centered Nursing Care

Table 5. CRC performance indicators of the studied healthcare providers

\begin{tabular}{lcc}
\hline & & No. (\%) \\
\cline { 2 - 3 } & Yes & No \\
\hline $\begin{array}{c}\text { Checking fecal occult blood } \\
\text { test in stool in the previous } \\
\text { year }\end{array}$ & $44(13.3)$ & $286(86.6)$ \\
\hline $\begin{array}{c}\text { Intention to undergo fecal } \\
\text { occult blood test in coming } \\
\text { months }\end{array}$ & $149(45.2)$ & $181(54.8)$ \\
\hline $\begin{array}{c}\text { Recommending to undergo- } \\
\text { ing the test to clients }\end{array}$ & $302(91.8)$ & $27(8.2)$ \\
\hline
\end{tabular}

Client- Centered Nursing Care

found that physicians and nurses had a desirable perceived sensitivity to CRC.

In the Shaouri Bidgoli (2015) study on Iranian patients referring to a health center in Qom, perceived sensitivity to CRC screening was low; it may be due to the lack of sample homogeneity and the lack of a screening program at the time. In this study, there was no significant relationship between demographic variables and perceived sensitivity.
Regarding perceived severity, the study participants scored higher than the instrument mean value, and most of them believed that it is highly dangerous if colon cancer is diagnosed late. Additionally, those with a family history of cancer, referring to a physician for digestive problems, had higher perceived severity. This finding was in line with those of some other studies (Pourhoseingholi \& Zali 2012; Almadi 2019). 
Regarding the perceived barriers dimension, the study participants' score was lower than the average, indicating that they had few barriers to screening. They cited the most important barrier as not receiving a physician's recommendation and the problems with stool collection, which has also been mentioned by other studies with different sample populations (Dolan et al. 2004; Christou and Thompson, 2012). The current study's sample required to educate others about screening, and screening for all people with a specific age group is necessary; measures are required to resolve these problems.

In terms of perceived benefits and perceived self-efficacy, the collected results were higher than the mean score of the instrument; therefore, the study participants have understood the benefits of screening. Besides, most of them believed that the timely detection of CRC would help to treat it and increase the odds of survival. However, FBOT screening was disregarded as the most effective diagnostic method. According to Salimzadeh et al. (2012) and Shouri Bidgoli et al. (2015), physicians were more likely to recommend colonoscopy screening and believed that FBOT screening was less sensitive; the difference of which can be attributed to that of guidelines (Shouri Bidgoli et al. 2015; Salimzadeh et al. 2012).

In the guidelines for practice, most information had been received through in-service training classes. Thus, it is required that special importance be given to these classes, and practitioners encourage to take part in these classes; try to increase people's sensitivity to CRC; explain the benefits of screening, and eliminate the barriers as much as possible. The awareness of the benefits of healthy behavior could encourage people to practice it (Shojaezadeh et al. 2012).

The achieved results highlighted that $13.3 \%$ of the study participants had performed a fecal occult blood test in the previous year. The age group of $\geq 50$ years had more tests taken, compared to the other age groups. This may be because the majority of investigated people were under 50 years old, and screening guidelines considered people aged 50-69 as the target group for this program. In our study, only $6.7 \%$ of the samples were in the age group of 50 years old. Moreover, in this age group, $68.2 \%$ had been screened for fecal occult blood.

Other studies have also found age to be important in screening (Christou \& Thompson 2012; Bidouei et al. 2014; Tahmasebi et al. 2016). The obtained data indicated that $45.2 \%$ of the samples intended to perform FBOT in the forthcoming months. Demographic variables were more influential in examining this performance with age $\geq 50$ years, a family history of cancer, and the male gender. Given that the target group for colorectal cancer screening was $\geq 50$ years, the collected results were expected to be acceptable.

Individuals with a family history of cancer were also expected to undergo more frequent screening because of their higher sensitivity. Wang et al. reported that women performed more screening than men, and the researcher articulated that women are more familiar with screening, such as tests for breast cancer and cervical cancer. (Wang et al. 2017). Other studies have reported a higher incidence of screening intention and screening action in individuals with a family history of cancer (Wang et al. 2017; Woudstra et al. 2016). The study of Bidori et al. and Bidgoli have suggested no relationship between a family history of cancer and performing a test (Bidouei et al. 2014; Shouri Bidgoli et al. 2015).

In total, $91.5 \%$ of the study subjects recommended FBOT testing to their clients according to the guidelines for CRC screening program. In some studies, the majority of staff recommended screening to their clients (Rim et al. 2009; Ramos et al. 2010); however, in Rim et al.'s study, physicians' and nurses' recommendations rate for FBOT screening was only $26 \%$, reflecting that this group requires further training.

The study participants had a positive attitude toward CRC screening. While performing periodic checkups and observing stool blood, problems with defecation and physician's recommendation were the most common causes of screening. Iran's healthcare system postponed CRC screening with fecal occult blood testing for many years. However, more attention is being paid to other studies in the field. Some studies in Iran has indicated that the existence of screening tests in the healthcare system insignificantly affects adults' tendency toward prevention and screening. Conducting similar programs for other non-communicable diseases and malignancies, like prostate cancer, is suggested.

\section{Ethical Considerations}

\section{Compliance with ethical guidelines}

Permission of the Ethics Committee of Iran University of Medical Sciences was obtained (Code: IR.IUMS. REC.1397.261.). Informed consent was obtained from all of the study participants.

\section{Funding}

The present paper was extracted from the MA.Thesis of the first author, affiliated to the Department of Community Health Nursing, School of Nursing and Midwifery, Iran University of Medical Sciences. 


\section{Authors' contributions}

Conceptualization: Elham khakbazalvandian, Marhamat Farahaninia, Daryadokht Masror Rodsari; Methodology: Elham khakbazalvandian, Marhamat Farahaninia, and Hamid Haghani; Investigation: Elham khakbazalvandian; Writing the original draft, writing-review and editing: Elham khakbazalvandian Marhamat Farahaninia; and Supervision: Marhamat Farahaninia.

\section{Conflict of interest}

The authors declared no conflicts of interest.

\section{Acknowledgments}

The authors appreciate the help of the Nursing and Midwifery Faculty, the Research Deputy of Iran University of Medical Sciences, Health Deputy of Ibnsina University, personnel of Health Center of Hamedan, and participants in the study.

\section{References}

Abuadas, F. H., Petro-Nustas, W. J. \& Abuadas, M. H., 2018. The effect of a health education intervention on Jordanian participants' colorectal cancer knowledge, health perceptions, and screening practices. Cancer Nursing, 41(3), pp. 226-37. [DOI:10.1097/NCC.0000000000000480] [PMID]

Almadi, M. A. \& Alghamdi, F., 2019. The gap between knowledge and undergoing colorectal cancer screening using the Health Belief Model: A national survey. Saudi Journal of Gastroenterology, 25(1), pp. 27-39. [DOI:10.4103/sjg.SJG_455_18] [PMID] [PMCID]

Azadeh, S., et al. 2008. Colorectal cancer in Iran: An epidemiological study. Asian Pacific Journal of Cancer Prevention, 9(1), pp. 123-6.

Azadeh, S., et al. 2012. Four years incidence rate of colorectal cancer in Iran: A survey of national cancer registry data-implications for screening. Asian Pacific Journal of Cancer Prevention, 13(6), pp. 2695-8. [DOI:10.7314/APJCP.2012.13.6.2695] [PMID]

Bidouei, F., et al. 2014. Knowledge and perception toward colorectal cancer screening in east of Iran. International Journal of Health Policy and Management, 3(1), p. 11. [DOI:10.15171/ ijhpm.2014.48] [PMID] [PMCID]

Bray, F., et al. (2018) Global cancer statistics 2018: GLOBOCAN estimates of incidence and mortality worldwide for 36 cancers in 185 countries. CA: A Cancer Journal for Clinicians, 68(6), pp. 394-424. [DOI:10.3322/caac.21492] [PMID]

Christou, A. and Thompson, S. C. (2012) Colorectal cancer screening knowledge, attitudes and behavioural intention among Indigenous Western Australians. BMC Public Health, 12(1), pp. 528. [DOI:10.1186/1471-2458-12-528] [PMID] [PMCID]
De Moor, J. S., et al. 2018. Colorectal cancer screening in the Unit ed States: Trends from 2008 to 2015 and variation by health insurance coverage. Preventive Medicine, 112, pp. 199-206. [DOI:10.1016/j.ypmed.2018.05.001] [PMID] [PMCID]

DeSantis, C. E., et al. 2019. Cancer statistics for African Americans, 2019. A Cancer Journal for Clinicians, 69(3), pp. 211-33. [DOI:10.3322/caac.21555] [PMID]

Dolan, N. C., et al. 2004. Colorectal cancer screening knowledge, attitudes, and beliefs among veterans: Does literacy make a difference? Journal of Clinical Oncology, 22(13), pp. 2617-22. [DOI:10.1200/JCO.2004.10.149] [PMID]

Fatemi, S. R., et al. 2010. Colonoscopy screening results in at risk Iranian population. Asian Pacific Journal of Cancer Prevention, 11(6), pp. 1801-4. [PMID]

Ghazali, A. K., et al. 2010. Prognostic factors in patients with colorectal cancer at Hospital Universiti Sains Malaysia. Asian Journal of Surgery, 33(3), pp. 127-33. [DOI:10.1016/S10159584(10)60022-X]

Gholampour, Y., et al. 2018. The effect of educational intervention based on health belief model and social support on the rate of participation of individuals in performing fecal occult blood test for colorectal cancer screening. Asian Pacific Journal of Cancer Prevention, 19(10), pp. 2777-87. [DOI:10.22034/APJCP.2018.19.10.2777] [PMID] [PMCID]

Glanz, K., Rimer, B. K. \& Viswanath, K., 2008. Health behavior and health education: Theory, research, and practice. Hoboken, New Jersey: John Wiley \& Sons.

Hou, S. I. 2005. Factors associated with intentions for colorectal cancer screenings in a Chinese sample. Psychological Reports, 96(1), pp. 159-62. [DOI: 10.2466/pr0.96.1.159-162] [PMID]

Jemal, A., et al. 2011. Global cancer statistics. A Cancer Journal for Clinicians, 61(2), pp. 69-90. [DOI:10.3322/caac.20107] [PMID]

Karimy, M., et al. 2012. [Pap smear test structures for measuring health belief model and factors affecting women in urban centers covered Zarandieh (Persian)]. Qom University of Medical Sciences Journal, 6(3), pp. 52-9.

Kharameh, Z. T., Foroozanfar, S. \& Zamanian, H., 2014. Psychometric properties of the Persian version of Champion's Health Belief Model scale for colorectal cancer screening. Asian Pacific Journal of Cancer Prevention, 15(11), pp. 4595-9. [DOI:10.7314/ APJCP.2014.15.11.4595] [PMID]

Mansour-Ghanaei, A., et al. 2015. Knowledge about colorectal cancer in Northern Iran: A population-based telephone survey. Asian Pacific Journal of Cancer Prevention, 16(17), pp. 78316. [DOI:10.7314/APJCP.2015.16.17.7831] [PMID]

Moghimi-Dehkordi, B. \& Safaee, A., 2012. An overview of colorectal cancer survival rates and prognosis in Asia. World Journal of Gastrointestinal Oncology, 4(4), pp. 71-5. [DOI:10.4251/ wjgo.v4.i4.71] [PMID] [PMCID]

Moradi, A., et al. 2009. Survival of colorectal cancer in Iran. Asian Pacific Journal of Cancer Prevention, 10(4), pp. 583-6. [PMID]

Ministry of Health and Medical Education., 2017. Package of essential non- communicable disease interventions for primery health care in iran, mojasameh. pp. 51-63. Tehran: Cheshmeh.

Ozsoy, S. A., Ardahan, M. and Özmen, D., 2007. Reliability and validity of the colorectal cancer screening belief scale in 
Turkey. Cancer nursing, 30(2), pp. 139-45. [DOI: 10.1097/01. NCC.0000265012.25430.30] [PMID]

Pourhoseingholi, M. A. \& Zali, M. R., 2012. Colorectal cancer screening: Time for action in Iran. World Journal of Gastrointestinal Oncology, 4(4), pp. 82-3. [DOI:10.4251/wjgo.v4.i4.82] [PMID] [PMCID]

Ramos, M., et al. 2010. Knowledge and attitudes of primary health care physicians and nurses with regard to population screening for colorectal cancer in Balearic Islands and Barcelona. BMC Cancer, 10(1), p. 500. [DOI:10.1186/1471-2407-10500] [PMID] [PMCID]

Rim, S. H., et al. 2009. Knowledge, attitudes, beliefs, and personal practices regarding colorectal cancer screening among health care professionals in rural Colorado: A pilot survey. The Journal of Rural Health, 25(3), pp. 303-8. [DOI:10.1111/ j.1748-0361.2009.00234.x] [PMID]

Safaee, A., et al. 2010. Characteristics of colorectal mucinous adenocarcinoma in Iran. Asian Pacific Journal of Cancer Prevention, 11(5), pp. 1373-5. [PMID]

Saffari, M., 2011. Health education E promotion: Theories, models $\mathcal{E}$ methods. Tehran: Asar-e Sobhan.

Salimzadeh, H., et al. 2012. Knowledge and practice of Iranians toward colorectal cancer, and barriers to screening. International Journal of Preventive Medicine, 3(1), pp. 29-35. [PMCID] [PMID]

Shojaezadeh, D., et al. 2012. Application of health belief model in prevention of osteoporosis in volunteers of Khorramabad City Health Centers, Iran. Health Services Research 8(2).

Shouri Bidgoli, A. R., et al. 2015. [A study of knowledge, attitude, and practice on colorectal cancer screening among individuals older than 50 years based on health belief model (Persian)]. Qom University of Medical Sciences Journal, 9(1), pp. 59-65.

Siegel, R. L., Miller, K. D. \& Jemal, A., 2019. Cancer statistics, 2019. A Cancer Journal for Clinicians, 69(1), pp. 7-34. [DOI:10.3322/ caac.21551] [PMID]

Skinner, C. S., Tiro, J. \& Champion, V. L., 2015. The health belief model; Health behavior: Theory, Research, and Practice (5th Edition). San Francisco: Jossey-Bass.

Tahmasebi, R., Noroozi, A. \& Dashdebi, K. G., 2016. Psychometric evaluation of the colorectal cancer screening belief scale based on health belief model's constructs for the fecal occult blood test. Asian Pacific Journal of Cancer Prevention, 17(1), pp. 225-9. [DOI:10.7314/APJCP.2016.17.1.225] [PMID]

Taylor, D. P., et al. 2010. Population-based family history-specific risks for colorectal cancer: A constellation approach. Gastroenterology, 138(3), pp. 877-85. [DOI:10.1053/j.gastro.2009.11.044] [PMID] [PMCID]

Wang, M. Y., et al. 2017. Knowledge, attitudes, preventive practices and screening intention about colorectal cancer and the related factors among residents in Guangzhou, China. Asian Pac J Cancer Prev. 18(12), pp. 3217-23. [DOI:10.22034/APJCP.2017.18.12.3217] [PMCID] [PMID]

Woudstra, A. J., et al. 2016. Knowledge, attitudes and beliefs regarding colorectal cancer screening among ethnic minority groups in the Netherlands: A qualitative study. Health Expectations, 19(6), pp. 1312-23. [DOI:10.1111/hex.12428] [PMID] [PMCID]
Zendehdel, K., 2019. Cancer statistics in IR Iran in 2018. Basic $\mathcal{E}$ Clinical Cancer Research, 11(1), pp. 1-4. [DOI:10.18502/bccr. v11i1.1645] 